\title{
Repensando a dependência após o Plano Real *
}

\author{
LÍDIA GOLDENSTEIN
}

\begin{abstract}
A REFLEXÃO TANTO SOBRE os rumos da economia brasileira após a implementação do Plano Real, quanto sobre a recente crise que tomou o Sudeste asiático de forma avassaladora, é extremamente oportuna e útil para avançarmos no debate sobre a dependência.
\end{abstract}

Em uma inversão de papéis inimaginável nos anos 80, quando o Brasil patinava em uma crise que, aparentemente, o levava a se distanciar cada vez mais dos centros dinâmicos do capitalismo internacional, e os países do Sudeste asiático eram considerados exemplos de sucesso na passagem do subdesenvolvimento para o desenvolvimento, assistimos, agora, o retorno do Brasil à órbita dos capitais internacionais enquanto na Ásia a crise se aprofunda cada vez mais.

O que teria ocorrido em apenas quatro anos que justificasse tamanha guinada? Como entender os processos atuais, tanto do Brasil quanto da Ásia?

Acredito que, quando escrevi Repensando a dependência (1), em 1994, estava no caminho certo: "os processos internacionais têm uma 'autonomia' no seu impacto sobre as regiões periféricas maior do que supúnhamos. Assim como as regiões periféricas têm menos 'autonomia' em suas decisões do que supúnhamos". Se isto já era verdade desde sempre, agora, com a globalização se intensifica.

A globalização aprofunda a dependência na medida que elimina a possibilidade, se é que alguma existe, de países se isolarem do mundo, de criarem barreiras e de tentarem um desenvolvimento autônomo.

Entendida como o aprofundamento do processo de internacionalização do capital, a globalização traz algo de novo na sua intensidade, na sua velocidade e, mais do que tudo, na revolução tecnológica que a sustenta e impulsiona. É a revolução tecnológica, principalmente no campo da telecomunicação, que permite o brutal desenvolvimento do sistema financeiro internacional e, com ele, não só o aumento do volume dos fluxos financeiros internacionais, mas também de sua volatilidade.

Obviamente, existem explicações sobre o como e o porquê do aumento dos fluxos de capitais financeiros sob a ótica do desenvolvimento do capitalismo inter-

\footnotetext{
* Post scriptun ao capítulo "Dependência e desenvolvimento", do livro Repensando a Dependência, publicado em 1994, pela Editora Paz e Terra. Este texto é baseado em trabalho que vem sendo realizado com José Roberto Mendonça de Barros nos últimos três anos.
} 
nacional. Entretanto, são as novas tecnologias que permitem a realização de transações financeiras internacionais imediatas, permitem a entrada e a saída de capitais de qualquer país, em qualquer lugar do mundo, permitem o acompanhamento de qualquer economia on line.

Traduzindo e simplificando, de qualquer orelhão da esquina qualquer pessoa que o queira pode colocar seu dinheiro em qualquer lugar do mundo. E isso não é trivial. Tal facilidade tem implicações profundas sobre as possibilidades e destinos dos países. A incompreensão deste simples fato, que foge ao nosso controle, tem levado a análises equivocadas de nossos caminhos e descaminhos.

Apesar da ilusão de autonomia (2), o ciclo de crescimento acelerado que tem início nos anos 50, conhecido como nacional desenvolvimentismo, só teve o fôlego apresentado graças ao financiamento externo que, em diferentes oportunidades, amorteceu as recorrentes crises de balanço de pagamentos e inflação. Somente nos anos 80 , quando no cenário internacional se aceleravam as transformações que acabariam conhecidas como globalização, o modelo de crescimento brasileiro se esgota, e é decisivo o papel das transformações internacionais neste esgotamento.

O aumento da mobilidade dos capitais muda o referencial nos quais são contabilizados os investimentos, quer financeiros, quer produtivos. A possibilidade de investimentos no exterior passa a ser uma alternativa de fácil acesso, levando à dolarização da economia. A fuga de capitais, até então uma variável econômica, se não inexistente pelo menos remota, passa a ser um perigo concreto.

Neste cenário, a inflação, cuja funcionalidade era indubitável no modelo anterior, dispara e perde sua funcionalidade, comprometendo todo o modelo. Ambos, a inflação e os recursos externos deixam de funcionar como amortizadores das crises e conflitos internos. Isto porque, sem o financiamento via inflação e/ou recursos externos, o Estado não tem como se financiar. Como o motor dinâmico do modelo era o gasto e o investimento público, sem este financiamento a economia entra em estagnação.

Assim, a dependência dos recursos externos que, embora sempre tenha existido, não era tão explícita e profunda, se agrava sobremaneira, a ponto de tornar inviável qualquer alternativa de reconstrução de um modelo de crescimento que não passasse pelo retorno do fluxo internacional de capitais para o país.

Os diferentes planos econômicos que se sucederam nos anos 80 (Cruzado, Bresser, Verão e Collor) são a prova disso. É só em meados dos anos 90, quando os fluxos de capitais internacionais voltam a se disponibilizar para o Brasil, que se consegue articular as condições para a economia se estabilizar e voltar a crescer. Entretanto, seguindo os velhos e bons cânones da Teoria da dependência, é preciso um olhar para as condições internas sem as quais, por maiores que fossem os fluxos de capitais internacionais que para cá se dirigissem (e eles não se dirigiriam), nenhum plano econômico teria tido sucesso em estabilizar a economia e, muito menos, em criar as condições para a retomada de um crescimento sustentado. 
O primeiro e decisivo passo para a viabilização das condições internas necessárias foi dado com a abertura da economia. É a abertura que permite o rompimento da "aliança inflacionária na qual setores empresariais, em conjunto com os setores mais organizados dos trabalhadores, protegiam-se da inflação às custas da aceleração do processo inflacionário" (3).

Esta aliança, “cuja 'conta' aparecia no déficit público e nas perdas de renda dos setores mais carentes e/ou desorganizados da sociedade" (4), tinha sua sobrevivência garantida pela falta de concorrência na economia.

Era o fechamento do país a base da estrutura econômica montada desde os anos 30. Garantindo uma reserva de mercado para as indústrias aqui instaladas (nacionais ou estrangeiras), o fechamento da economia desobrigava-as de novos investimentos, de pensar em custos e aumentos de produtividade. Quaisquer custos, inclusive salariais, podiam automaticamente ser repassados para preços. E os incentivos à modernização tecnológica eram nulos.

Ao romper esta proteção, a abertura introduz a concorrência na economia, obrigando a mudança do paradigma produtivo (5). As empresas são forçadas a passar por transformações radicais no seu posicionamento estratégico, nas suas operações internas e no relacionamento interno das cadeias produtivas.

Ao provocar tal mudança paradigmática, a abertura da economia, por sua vez, viabiliza a estabilização. Com a economia fechada, sem concorrência, era impossível romper com as práticas das empresas de jogarem quaisquer custos para preços. Não havia necessidade de as empresas se esforçarem por diminuir custos, buscar aumentos de produtividade, investir em geral. O mercado lhes era dado, garantido juntamente com margens de lucro especialmente elevadas, se comparadas com as de outros países.

Além de forçar a mudança do paradigma da economia e viabilizar a estabilização, a abertura tem forte impacto redistributivo. "A abertura provoca uma brutal transferência de renda para o consumidor, correspondente às tarifas que deixam de ser pagas ao governo, à quase renda (sobre-preço) que os empresários obtinham com a reserva de mercado e aos ganhos de eficiência que necessariamente ocorrem na economia, inclusive pela escala" (6) "Dada a conhecida concentração de renda brasileira e a conseqüente demanda reprimida da população, uma transferência de renda do porte da ocorrida com a abertura amplia significativamente o mercado consumidor, a ponto de afetar positivamente as decisões de investimento das empresas, não só as das já instaladas, como de importantes empresas internacionais que passam a olhar o mercado brasileiro com outros olhos" (7).

"A estabilização, por sua vez, também contribui significativamente para a ampliação do mercado, não só graças ao ganho concreto que dá para as faixas mais baixas da população, as que mais perdiam com o processo inflacionário, como pelo impacto que tem sobre o crédito. Após anos ganhando com o float, o controle da inflação fez com que o sistema financeiro voltasse a ter no crédito uma de suas 
atividades básicas, criando condições para que segmentos importantes da população entrassem no mercado consumidor. Portanto, ambas, a abertura e a estabilização, somadas ao sucesso da consolidação do Mercosul enquanto um mercado único, criaram um mercado de tal monta que foi capaz de reverter positivamente as decisões de investimento das empresas nacionais e estrangeiras, em diferentes setores da economia.

Porém, o efetivo retorno dos investimentos só ocorre porque, além da transferência de renda para os segmentos que mais perdiam com a inflação e da criação de condições para a volta do crédito, a estabilização e a abertura recriam as condições de segurança aos investidores, que passam a ter um horizonte de médio e longo prazo fundamentais para as decisões de investimento, impossível em momentos de grande instabilidade econômica decorrente de altas taxas inflacionárias.

Assim, abertura da economia associada à estabilidade resultou em uma guinada radical na direção na qual as decisões de investimento vinham tomando" (8). Tem início o que chamamos de terceira onda de investimentos internacionais (após as dos anos 50 e 70 ) a qual, via investimentos diretos, passa a garantir um fluxo de capitais externos positivo, fundamental tanto para a abertura quanto para a estabilização. Entretanto, dada a importância de um fluxo não só positivo mas volumoso e rápido de recursos externos, este também é garantido mediante a elevação das taxas de juros internas que, via diferencial com as taxas externas, garante um fluxo positivo de capitais especulativos.

Além da globalização, da abertura e da estabilização, um quarto processo contribui decididamente para a revolução pela qual vem passando a economia brasileira. É a privatização que, além de contribuir para a atração de capitais externos, tira de cena a empresa estatal, um dos pilares do antigo tripé que sustentava o capitalismo brasileiro. Começa então a delinear-se uma nova correlação de forças, na qual não só as estatais perdem seu espaço, como também as tradicionais empresas nacionais familiares e as estrangeiras aqui instaladas, atuando ambas no velho paradigma da ineficiência.

Apesar das dificuldades, uma nova ordem começa a se estabelecer, possibilitando o reforço das condições positivas que lhe deram início. É um círculo virtuoso que, entretanto, depende profundamente dos caminhos e descaminhos traçados pelo jogo de forças e interesses internos ameaçados e/ou em construção. Não existe qualquer caminho pré-estabelecido e, muito menos, garantia de sucesso na reorganização da economia. A passagem da estabilização para uma fase de crescimento sustentado é dolorida, custosa e perigosa, como sempre enfatizamos.

Todo o processo depende da manutenção da economia aberta, para garantir o controle da inflação e a fuga de capitais. A manutenção da economia aberta exige, por sua vez, a existência de moeda forte para garantir as importações e para impedir ataques especulativos contra a sua moeda, ainda frágil. Para obter moeda forte existem dois caminhos: atrair capitais especulativos por meio de elevadas taxas de juros ou atrair capitais produtivos. O primeiro, atração de capitais especulativos, 
é um caminho perigoso, custoso e de fôlego curto. Os capitais especulativos saem ao perceber a fragilidade da economia que os está atraindo. O caminho mais sólido é o da reestruturação produtiva que garanta uma inserção internacional menos frágil. Sem dúvida o Plano Real dependeu, e ainda depende em certa medida, de capital externo especulativo mas, ao mesmo tempo, criou as condições para a vinda de investimentos diretos que, ao contribuírem para a reestruturação produtiva, permitem o retorno de um crescimento sustentado.

No mundo globalizado a dependência do capital externo é maior do que nunca. O mesmo Plano Real implementado em outro momento, quando as condições externas fossem outras, não teria dado resultado. Entretanto, sem condições internas o Plano também teria fracassado. O esgotamento do modelo nacional desenvolvimentista e a fartura da sociedade após 15 anos de inflação e estagnação desarticularam o arranjo até então existente. A abertura e a privatização viabilizam a estabilização e os três processos em conjunto permitem a construção de uma nova estrutura econômica, baseada em um novo paradigma, cuja consolidação é o único caminho para minimizar os eternos percalços colocados pela dependência.

Notas

1 Ver Goldenstein, Lídia. Repensando a Dependência. Rio de Janeiro, Paz e Terra, 1994.

2 Id. Ver capítulo II: A ilusão da autonomia: ascensão e queda de um padrão de financiamento.

3 Ver Mendonça de Barros, José Roberto \& Goldenstein, Lídia. Plano Real Fase II: da estabilização ao crescimento sustentado . Trabalho apresentado no X FÓRUM NACIONAL, maio 1998.

4 Id.

5 Sobre o novo paradigma produtivo, ver Abranches, Sérgio H. \& Fleury, Paulo F. Competitividade e politicas públicas: Uma agenda para o Brasil Trabalho apresentado em seminário organizado pela SPE/MF e BNDES, set. 1997; Mendonça de Barros, José Roberto \& Goldenstein, Lídia. A crise asiática e a estabilização no Brasil. $O$ Estado de S. Paulo, 14 dez. 1997.

6 Ver Mendonça de Barros, José Roberto \& Goldenstein, Lídia. Avaliação do processo de reestruturação industrial do Brasil. Revista de Economia Política, n. 2, abr./jul. 1997.

7 Id.

8 Ibid.

Lídia Goldenstein, economista e doutora pela Unicamp, é assessora da presidência do BNDES (Banco Nacional de Desenvolvimento Econômico e Social). 